\title{
Performance Investigation of Switched Reluctance Motor Drive with various Converter Topologies
}

\author{
Adita Saini, Ajay Srivastava
}

\begin{abstract}
Switched Reluctance Motors are used for variable speed application at very high speed. In this motor the losses are less and efficiency is more because there are no windings on the rotor. But torque pulsations in SRM are relatively higher compared to other ac machines due to nonlinear inductance profile. Both, machine design and electronic control approaches have been used to minimize the torque ripples in SRM to achieve better performance of SRM drive system. The objective of this paper is to investigate performance of 6/4 switched reluctance motor with fuzzy logic controller with various converter topologies i.e. asymmetric converter, R-Dump converter, miller converter and modified power converter. The present work also concentrates on the modeling of SRM drive with fuzzy logic controller for SRM speed control by using MATLAB/Simulink environment. The fuzzy logic controller is designed using simulink toolbox.
\end{abstract}

Keywords - Switched Reluctance Motors, Convertor topologies, torque ripples.

\section{INTRODUCTION}

The switched reluctance motor (SRM) is becoming more and more popular for high speed industrial application due to its rugged and robust construction. In this motor the losses are less and efficiency is more because there are no windings on the rotor. But the torque pulsations in SRM are relatively higher compared to sinusoidal machines due to the doubly salient structure of the motor due to nonlinear inductance profile and pulse magnetizing. To make it suitable for constant speed application, both machine design and electronic control approaches have been used to minimize the torque ripples in SRM drive to achieve better performance of SRM drive system. The main objective of this paper is to investigate the performance of switched reluctance motor drive. The typical SRM drive consists of four basic components; power converter, control logic circuit, position sensor and switched reluctance motor. The block diagram of SRM drive is shown in figure 1 . To achieve the above objective, torque and speed control are provided in this study using different converter topology. Where torque performance improvement is provided through current control by using hysteresis loop control and for speed performance improvement closed loop control is used by providing a speed controller. Here fuzzy logic controller is used as speed controller. Fuzzy logic controller (FLC) is an

Adita Saini: Student, Dept. of Electrical Engg. College of Technology, GBPUA\&T Pantnagar Distt. Udham Singh Nagar, India

Ajay Srivastava: Professor, Dept. of Electrical Engg. College of Technology, GBPUA\&T Pantnagar Distt. Udham Singh Nagar, India intelligent controller which uses fuzzy logic to process the input. Fuzzy logic is a many valued logic which is much like human reasoning. In industrial control FLC has various applications, particularly where conventional control design techniques are difficult to apply. The power converter circuit in this switched reluctance motor drive plays a very important role. The optimum performance of SRM depends upon the appropriate positioning of the currents relative to rotor position. The current should be unidirectional in this motor, so the converter circuit should consist of a minimum number of switches. The power converter is the heart of the motor drive. The performance, size, and the cost of the motor drive are mainly depends upon the selected converter type of the power converter circuit. So this study includes the comparison of different converter types used with 3-ph 6/4 SRM. The power converter types those are involved in this study are asymmetric converter, R-Dump converter, miller converter and modified power converter. The modelling of SRM drive system is carried out in Simulink/MATLAB environment.

\section{SWITCHED RELUCTANCE MOTOR}

Switched Reluctance Motor is a singly excited, doublysalient machine with field coils on stator and without any winding on rotor, in which the electromagnetic torque is developed due to variable reluctance principle. When the excitation is given to the stator windings, a force is created by rotor magnetic reluctance that try to align the rotor pole with the adjacent stator pole.

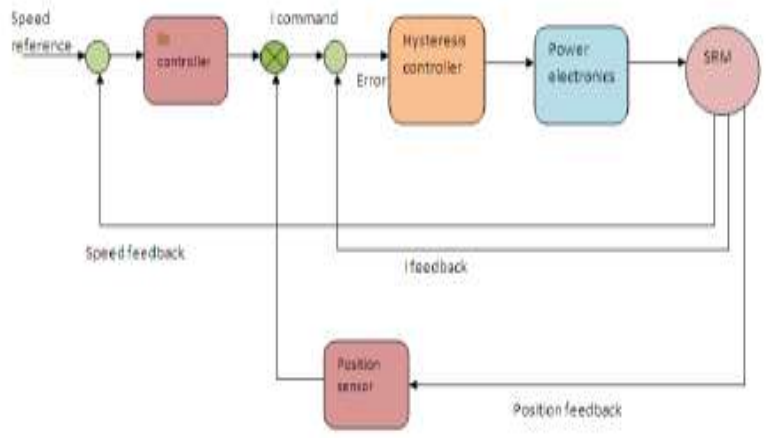

Fig. 1: Block diagram of closed loop SRM drive

In order to preserve sequence rotation, the windings of stator pole switches in a sequential manner with the help of electronic control system so that the magnetic field of rotor pole was lead by the stator pole, pulling towards it. The rotor 
pole is said to be "fully unaligned position" when the rotor pole is equidistant from the two adjacent stator pole. This position is called as maximum magnetic reluctance for the rotor pole. In aligned position the rotor poles are fully aligned with the stator poles, this position is called as minimum reluctance of rotor pole. Figure. 2 illustrates the 6/4 SRM drive which consists 6 stator poles and 4 rotor poles. The voltage equation of SRM is given below,

$$
\begin{aligned}
& V=r i+d \Phi l / d t \\
& \psi=\mathrm{Li}=\mathrm{N} \varphi
\end{aligned}
$$

Say $\mathrm{r}=0$

$$
\begin{aligned}
& \mathrm{V}=\mathrm{Ldi} / \mathrm{dt}+\mathrm{i}(\mathrm{dL} / \mathrm{d} \theta)(\mathrm{d} \theta / \mathrm{dl}) \\
& \mathrm{V}=\mathrm{L} \mathrm{di} / \mathrm{dt}+\mathrm{i} \omega(\mathrm{dL} / \mathrm{d} \theta) \\
& \mathrm{T}=1 / 2 \mathrm{i}^{2}(\mathrm{dL} / \mathrm{d} \theta)
\end{aligned}
$$

The above equation shows that the developed torque depends only on current magnitude and $\mathrm{dL} / \mathrm{d} \Theta$ and it is independent of current direction.

\section{Power converters for switched reluctance motor}

(A) Asymmetric bridge converter

This converter(fig.3) consists of two power switches and two diodes per phase of SRM. Here the numbers of elements used are more per phase. It is one of the major disadvantages of this converter. In this converter the two switches go off when the current exceeds the commanded current value. The energy stored in the motor winding keeps the current in the same direction until it is depleted. The two diodes then come in to action leading to recharging the source.

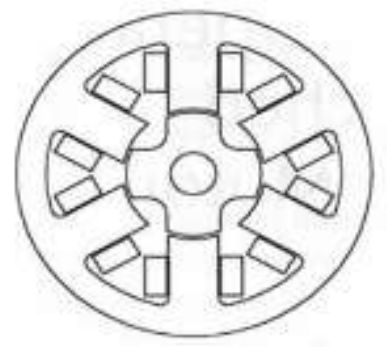

Fig. 2: Structure of $6 / 4$ SRM

(B) R-Dump converter

This converter was proposed by R. Krishnan. In this converter the capacitor Cs value always depends on the Dump resistance $\mathrm{R}$. The R- dump converter for three phases SRM is shown in Fig.4. This converter consists of a minimum number of switches as compared with an asymmetrical bridge converter. In this converter each phase has one switch and one diode as shown in Fig4. The switch T1 will be off only when the current exceeds the commanded current value. Then the diode D1 freewheels. This same process will take place for the remaining three phases also. The Major disadvantage of this converter is that the inductor energy is wasted in the dump resistance causing low overall efficiency.

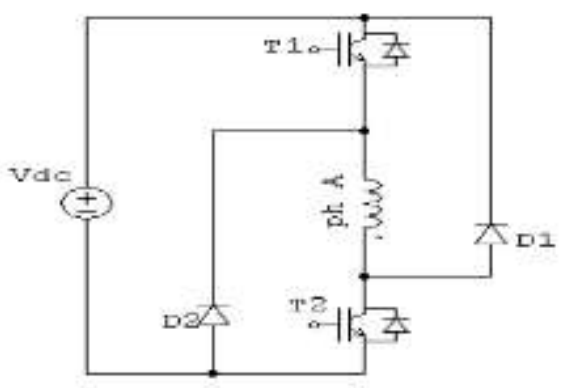

Fig. 3: Asymmetric bridge converter

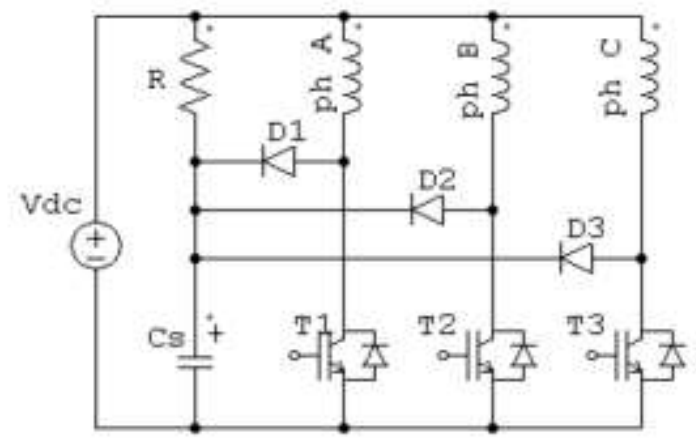

Fig. 4: R-Dump converter

(C) Miller converter

A miller converter circuit is shown in Fig 5. In a miller converter circuit for q phase motor one transistor is common to all the phases for the control of current, while the other transistor are used for the proper operation of the phases. This type of converter circuit directs the excess energy back to the source through a diode. When transistor T1 and T2 are ON, current flows through phase 1 . When transistor $\mathrm{T} 2$ is off and T1, T3 are switched ON, then current flows through phase2 and phase 1 current do not reduces to zero as it freewheels through T1 and D1. Similarly when T2, T3 are off, and T1, T4 are $\mathrm{ON}$, current flows

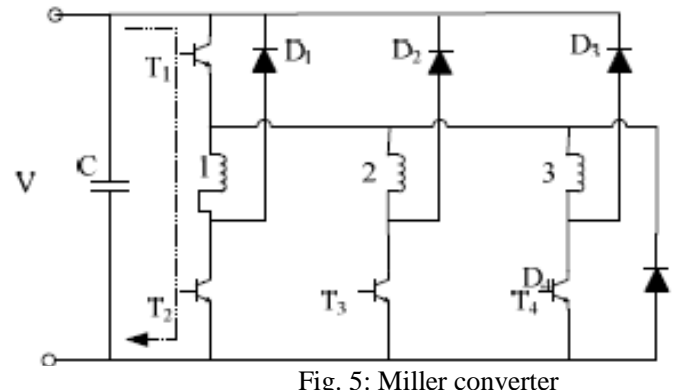

through phase 3 and phase 1 and phase 2 currents do not reduce to zero as it freewheels through T1, D1 and T1, D2. Again when phase 1 is switched on then current in phase 2 and phase 3 has not reduced to zero. Hence at higher speeds the current start rising in each phase before reaching the zero value causing negative torque and excessive heat in the windings. Miller converter is having $(\mathrm{q}+1)$ switches for $\mathrm{q}$ phases. 
Although it reduces the number of switches, the problem of overlapping of phase currents at higher speeds creates a problem of negative torque.

\section{(D) Modified power converter}

A modified power converter is shown in fig. 6 where number of devices is less than classic bridge converter but more than miller converter. Here the problem of overlapping of phase currents has been improved which facilitates all the phase current to decay to zero. The working of this converter can be analyzed using figure 6.When transistor $\mathrm{T} 1$ and $\mathrm{T} 21$ are switched ON current flows through phase 1 . When T1, T21 are off and T22, T3 are switched on then current flows through phase 2 and phase 1 current reduces to zero through D21 and D1. Similarly when T22, is off and T3, T4 are switched on current flows through phase 3 then phase 1 current reduces to zero and phase 2 current do not reduces to zero as it freewheels through T3, D22. Again when phase1 is switched on then current in phase 3 and phase 2 reduces to zero. Here only phase 2 current takes time to reduce to zero. But all the phase currents reduce to zero. Here we observe that during starting torque and current is high but after some time current reduces to a fix value.

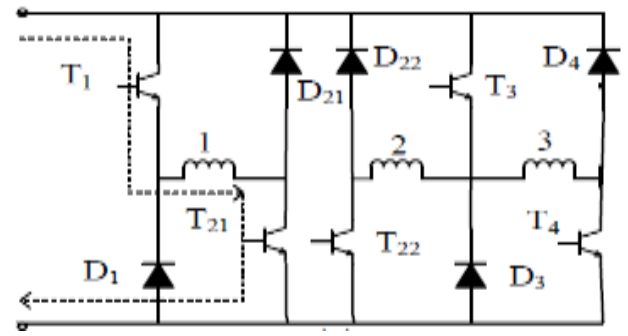

Fig. 6: Modified power converter

\section{Simulink Model}

\section{Parameters and Assumptions of SRM drive}

The switched reluctance motor is based on certain assumption, those are given below

- Stator and rotor is having same pole arc, $\beta \mathrm{s}=\beta \mathrm{r}$

- Magnetic saturation is neglected

- Mutual inductance is neglected

- Stroke angle, the angle at which rotor moves when we give stator excitation in SRM is $2 \pi / \mathrm{q} \mathrm{Nr}$, where $\mathrm{q}$ is the number of phases and $\mathrm{Nr}$ is the number of rotor poles.

- Inside the position sensor we produce signals for each stroke angle. In 90 degree, each phase will be excited once. In 360 degree, i.e. one revolution cycle, each phase will be excited four times.

The simulink model of switched reluctance motor drive with FLC are shown in fig. 7.

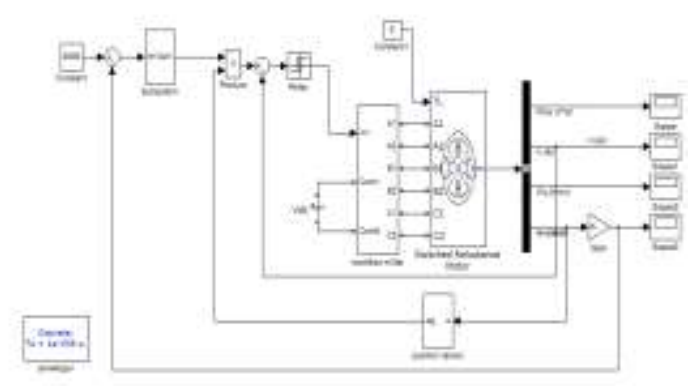

Fig.7: Simulation diagram of SRM drive with FLC

Fuzzy logic was proposed by Lotfi Zadeh in 1965, it has various applications in all inventive fields. The merits of fuzzy logic controller are the clarification for a problem can be easily analyzed and the design of the controller can be implemented.The four main stages in fuzzy logic controller: fuzzification, rule base, inference mechanism and defuzzification. The fuzzification is nothing but it comprises the process of transpose crisp values into grades of membership for linguistic terms of fuzzy sets. The transpose from a fuzzy set to a crisp number is called a defuzzification. The inference engine and the knowledge base were the components of an expert system. The knowledge base stores the factual knowledge of the operation of the concern experts. Fuzzy inference engine is the process of calculating from a given input to an output using fuzzy logic. In inference engine, If -Then type fuzzy rules converts fuzzy input to the output. Mamdani type fuzzy logic controller is most commonly used in a closed loop control system, because it reduces the steady state error to zero. The designed fuzzy rules used in this research are the fuzzy sets which have been defined as: negative large (NL), negative medium (NM), negative small (NS), zero (ZR), positive small (PS), positive medium (PM) and positive large (PL) respectively. Many research papers have developed SRM models based on fuzzy logic. The simulink model is designed for the speed control of Switched Reluctance Motor using Fuzzy logic controller is shown in Figures 8-10.

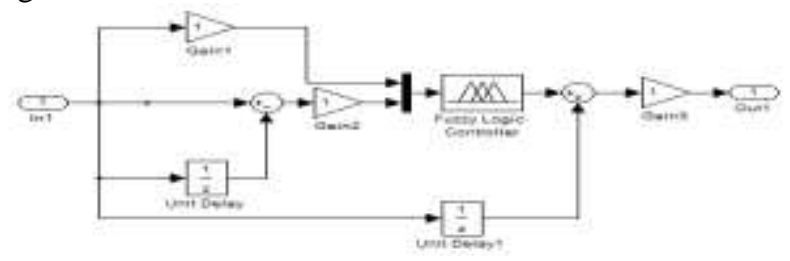

Fig.8: Simulation diagram of fuzzy logic controller

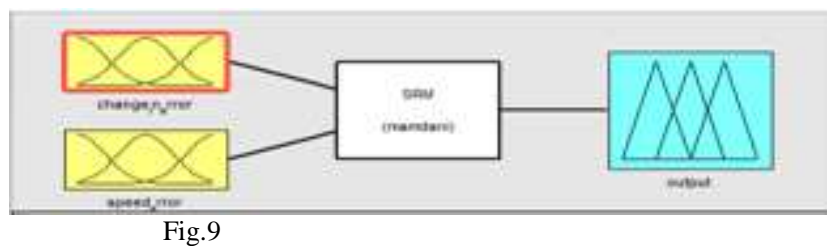

Fig.9 


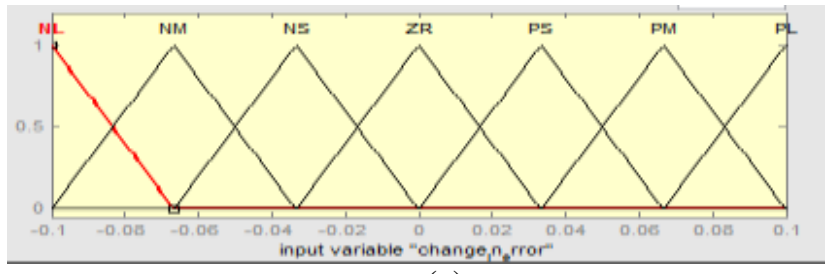

(a)

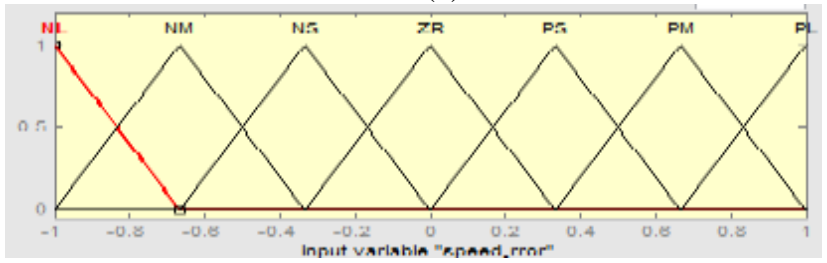

(b)

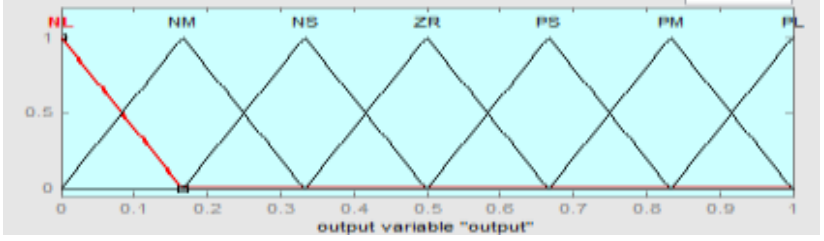

(c)

Fig.10: Fuzzy membership function (a) change in speed error (b) speed error (c) output speed

$V$. Results

(A) SRM drive with asymmetric converter

Closed loop SRM drive with fuzzy logic controller

The performance characteristics like torque and speed of SRM drive with fuzzy logic controller is shown in figure 11.

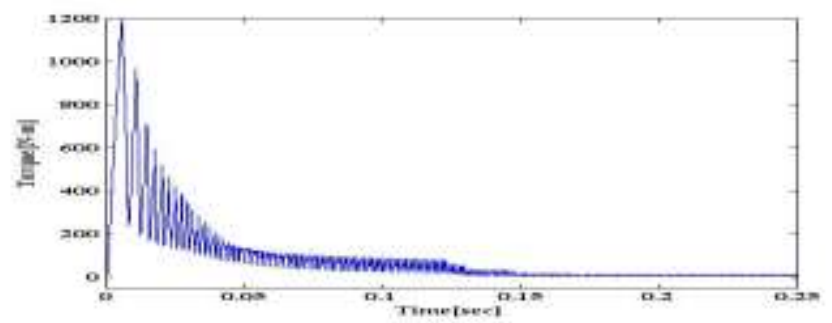

(a)

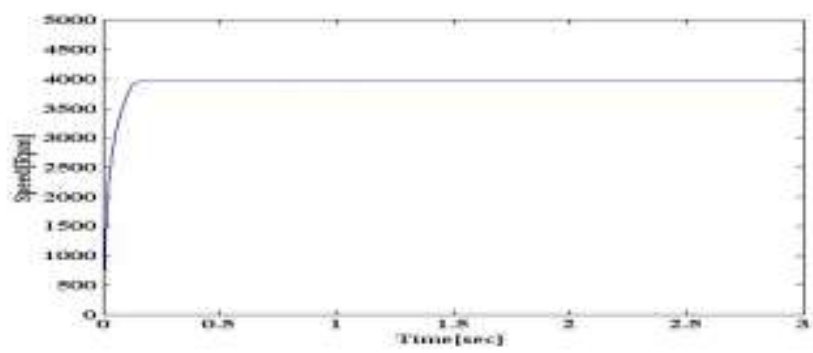

(b)

Fig.11: performance characteristics of SRM drive with FLC (a) torque (b) speed

The SRM drive start at time $\mathrm{t}=0$ from no load. The reference speed is adjusted to value of $4000 \mathrm{rpm}$. The current is very high at starting but settle down to a low value after some time. Torque is very high at start which is good for starting of motor but reduce after some time. In this case torque ripples are less.
So torque performance is improved in this case. The speed is settle down at time $\mathrm{t}=0.15$ or reaches to steady state. So the settling time is 0.15 second with fuzzy logic control in closed loop circuit with asymmetric converter. The speed performance is better in this case with fuzzy logic control.It gives a smooth control of speed response and settling time is also reduces.

\section{(B) SRM drive with R-Dump converter}

Closed loop SRM drive with fuzzy logic controller The performance characteristics like torque and speed of SRM drive with fuzzy logic controller is shown in figure 12 .

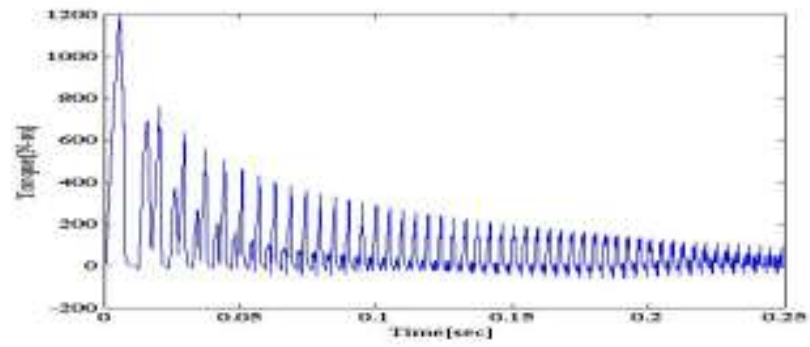

(a)

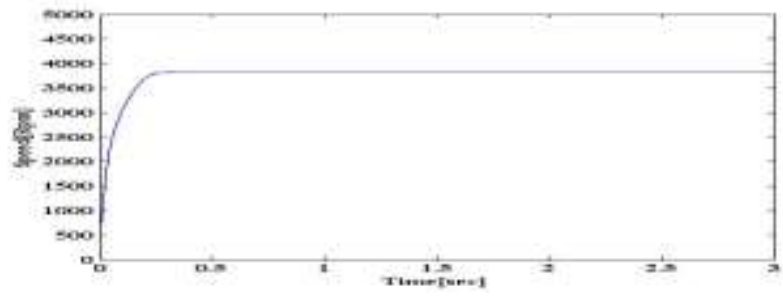

(b)

Fig. 12: Performance characteristics of SRM drive with FLC (a) torque (b) speed

The SRM drive start at time $\mathrm{t}=0$ from no load. The reference speed is adjusted to value of $4000 \mathrm{rpm}$. The current is very high in starting and then reduces to a low value after some time. Torque is high at start which is good for starting and torque ripples are also reduces. The torque performance is improved in this case. The speed is settle down at time $\mathrm{t}=0.25$. So the settling time is 0.25 second with fuzzy logic control in closed loop circuit with R-Dump converter. The speed performance is better. But poor in comparison to asymmetric converter because settling time increases and speed is also reduces from desired value. It gives a smooth curve of speed response.

(C) SRM drive with miller converter

Closed loop SRM drive with fuzzy logic controller

The performance characteristics like flux, current, torque and speed of SRM drive with fuzzy logic controller is shown in figure 14. The SRM drive start at time $t=0$ from no load. The reference speed is adjusted to value of $4000 \mathrm{rpm}$. The speed is settle down at time $t=0.15$. So the settling time is 0.15 second but with reduced speed with fuzzy logic control in closed loop 
circuit with Miller converter. It gives a smooth curve of speed response. The torque characteristic has fewer ripples in closed loop circuit. Torque at start of motor is very high which is good for starting.

\section{(D) SRM drive with modified power converter}

Closed loop SRM drive with fuzzy logic controller

The performance characteristics like flux, current, torque and speed of SRM drive with fuzzy logic controller is shown in figure 13 .

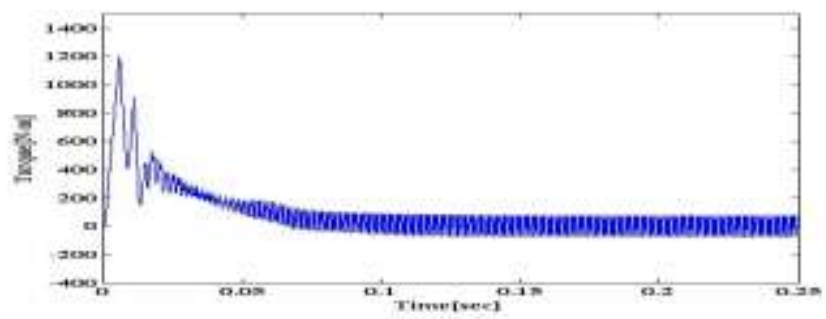

(a)

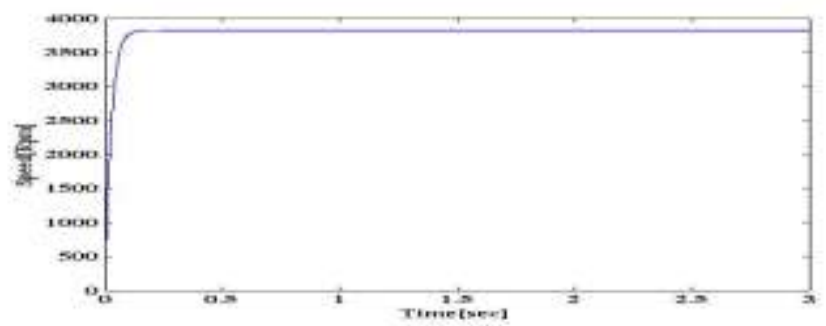

(b)

Fig. 13: Performance characteristics of SRM drive with FLC (a) torque (b) speed

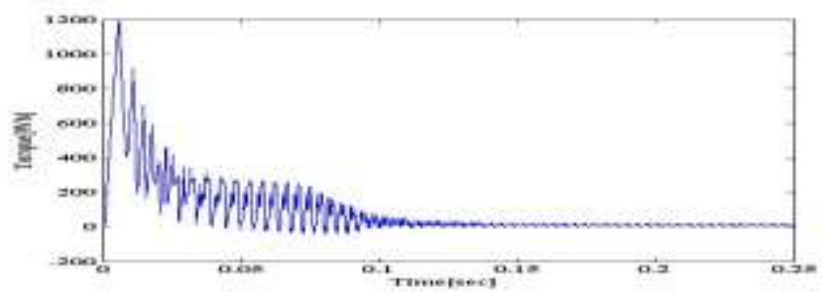

(a)

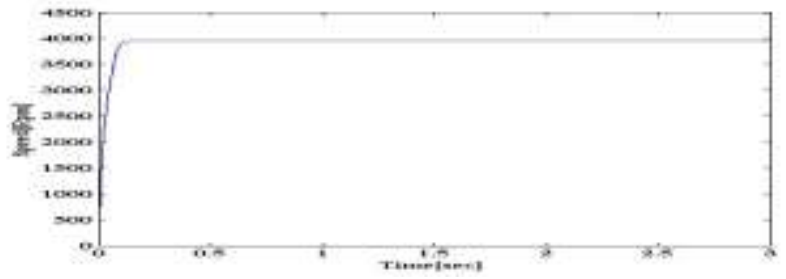

(b)

Fig. 14: Performance characteristics of SRM drive with FLC (a) torque (b) speed

The SRM drive start at time $\mathrm{t}=0$ from no load. The reference speed is adjusted to value of $4000 \mathrm{rpm}$. In this case also current has very high starting value and reduces when motor reaches to its running speed. In modified miller converter with FLC, torque has very high starting value which is good for starting of motor and reduces to a low value when motor reaches to its running speed. Torque ripples also reduce as compare to open and PI control. The speed is settle down at time $\mathrm{t}=0.15$. So the settling time is 0.15 second with fuzzy logic control in closed loop circuit with modified power converter. The speed characteristic is better in case of fuzzy logic control. It gives a smooth curve of speed response.

\section{CONCLUSION}

For achieving better performance of SRM drive. closed loop fuzzy logic control shows best results for improving the speed performance. According to results asymmetric converter with fuzzy logic control and modified power converter with fuzzy logic control give similar performances. If both converters are compared, modified power converter shows better performance in case of torque ripple reduction. For improving the torque and speed performance modified power converter with fuzzy logic control is best suited.

\section{REFERENCES}

[1] Ch., Sunita and Srikanth, M.V., "Modeling and Analysis of 6/4 Switched Reluctance Motor with Torque Ripple Reduction", IOSR Journal of Electrical and Electronics Engineering, 2014, pp. 37-42.

[2] Gairola, S., Priti. and Paliwal, L. N., 2010. "A New Power Converter for SRM Drive." IEEE, 1-6., 2010

[3] Zeljko, Grbo, Vukosavic, Slobodan and Emil, Levi., "A Novel Power Inverter for Switched Reluctance Motor Drives", FACTA UNIVERSITATIS (NIS),18(3), 2005, pp. 453-465.

[4] Krishnan, R., Materu, P.N., "Design of a Single-Switch-Per-Phase Converter for switched Reluctance Motor Drives," IEEE Transaction on Industrial Electronics, 37(6), 1990, pp. 469-476.

[5] Kumar, K.; Murthy, G. R. K. and Addala, Srinivas, S. S., “Open Loop and Closed Loop Performance of Switched Reluctance Motor with various Converter Topologies." International Journal of Power Electronics and Drive System. 5(1), 2014, pp. 83-92.

[6] Miller, T. J. E., "Brushless Reluctance Motor Drives", IEEE Power Engineering Journal, 1, 1987, pp. 325-331.

[7] Peter, Joseph, "Modeling \& Torque Ripple Minimization of Switched Reluctance Motor for High Speed Applications."International Journal of Science and Modern Engineering,1(10), 2013, pp. 15-20.

[8] Prasad, Nisha and Jain, Shailendra, "Simulation of Switched Reluctance Motor for Performance Analysis Using MATLAB/SIMULINK Environment and use of FPGA for its control." International Journal of Electrical, Electronics and Computer Engineering, 1(1), 2012, pp. 91-98.

[9] Sindhuja, S. and Susitra, D. , "Design of a Novel High Grade Converter for Switched Reluctance Motor Drive using Component Sharing." IEEE,11741178.2013, pp.

[10] Srivastava Kiran, Singh B. K., Arya K. V. And Singh R. K. 2011. "Simulation and Modelingof 8/6 Switched Reluctance Motor Using Digital Controller". International Journal of Electronics Engineering, 3(2), 2011, pp. 241-246.

[11] Kiruthika D. And Susitra D. , "Speed Controller of Switched Reluctance Motor".Indian Journal of Science and Technology,7(8), 2014, pp. 10431048. 